ojs.uv.es/index.php/qfilologia/index

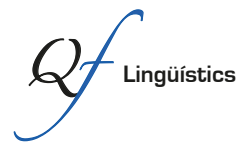

Per a citar aquest article: Maruenda-Bataller, Sergio; Palau Sampio, Dolors \& Taboada, Maite. 202I.

"Los discursos de género, violencia y desigualdad social en la era de la comunicación (digital)".

Quaderns de Filologia: Estudis Lingüístics XXVI: 9-I7.

doi: $10.7203 /$ QF.26.22047

\title{
Los discursos de género, violencia y desigualdad social en la era de la comunicación (digital)
}

The discourses of Gender, Violence and Social Inequality in the era of digital communication

\author{
Sergio Maruenda-Batalle R \\ Universitat de València \\ sergio.maruenda@uv.es \\ Dolors Palau Sampio \\ Universitat de València \\ dolors.palau@uv.es \\ Maite TABoAda \\ Simon Fraser University \\ mtaboada@sfu.ca
}

Este volumen tiene como objetivo estudiar y analizar los discursos públicos en torno al género, la violencia y la desigualdad social en los llamados medios digitales (Couldry, 20I2) y, más concretamente, su evolución e impacto político, cultural, social e ideológico en la era digital y las "nuevas" formas de comunicación social, institucional y política (Fuchs, 2007; Bennet \& Segerberg, 20I3; Winseck, 20I7). La edición pretende profundizar en los discursos generados y canalizados a través de la llamada sociedad en red (Castells, 20II), cuando se celebra el primer cuarto de siglo de vida de internet. El presente volumen adopta una aproximación teórica crítica y comunicativa en el análisis de los discursos actuales que construyen $y$ constituyen lingüística $y$ discursivamente el género, la violencia y la desigualdad social (Critical Discourse Studies, Flowerdew \& Richardson, 2018), como formas de representación cognitiva y social que pueden acontecer hegemónicas o periféricas (Wodak \& Meyer, 200I; Lazar, 2005; Fairclough, 2006; Butler, 2006; van Dijk, 2008; Cotter, 20I0; Erlich, Meyerhoff \& Holmes, 20I4). 
Los medios de comunicación (digitales) son fuentes importantes de definiciones e imágenes de la realidad social y, por tanto, contribuyen de forma esencial a la construcción de esta mediante procesos de re-significación. En su tratamiento de los temas sociales, los medios conforman y registran de manera crucial la forma en que la cultura, la política y la vida social se construyen a través del discurso (Bell, I998; Cotter, 20I0). Podemos, por tanto, argumentar que el discurso de los medios transmite esquemas culturales e ideologías que dan forma y controlan las percepciones y representaciones sociales tanto de los hechos como de los agentes (van Dijk, I988).

La interrelación entre el discurso de los medios y la transmisión de ideología ha sido ampliamente investigada desde el análisis crítico del discurso (ACD) (véase, por ejemplo, Bell, I99I; Fowler, I99I; Bell \& Garrett, I998; van Dijk, I998; Richardson, 2007). Este análisis es clave para comprender su influencia en la percepción y cognición social sobre temas y hechos relevantes (Fairclough, I995). Desde estas consideraciones, el presente volumen recoge investigaciones que problematizan y analizan de forma crítica la ideología subyacente a diversos temas de género, violencia y desigualdad social y su construcción en una multiplicidad de discursos.

Desde el constructivismo, el discurso mediático se define como el producto final de un proceso complejo de selección de temas y acontecimientos guiada por un conjunto de factores intrínsecos de naturaleza social (Westerståhl \& Johansson, I994; Palmer, 2000), cognitiva (van Dijk, I988; Fowler, I99I) y discursiva (Bednarek \& Caple, 20I7): los valores noticiosos (news values). Sin embargo, estos valores no son intrínsecos a la naturaleza de los hechos noticiables, sino que constituyen un acto de interpretación en cuya representación discursiva intervienen factores de índole política, social y económica (Cole \& Harcup, 20Iо; Cotter, 20Iо).

En esta construcción social intervienen varios aspectos cruciales. En primer lugar, las historias se construyen a partir del interés periodístico para una determinada audiencia (Durant \& Lambrou, 2009), en función de las fuentes e ideologías concretas. En segundo lugar, como corolario, al presuponer sus intereses, las noticias construyen a la audiencia, a menudo difuminando los límites entre el mero consumo y el derecho a estar informado (Tabbert, 20I6). Por último, el lenguaje es solo aparentemente objetivo. La supuesta neutralidad de las instituciones mediáticas emana de su ámbito de actuación en el discurso público y de su imparcialidad sobre las percepciones y los argumentos, pero esta a menudo responde a una agenda oculta (Wodak \& Meyer, 200I; Wodak \& Busch, 2004). 
No obstante, desde la investigación periodística, Cole y Harcup (20I0) sostienen que las reflexiones del ACD sobre los matices ideológicos a menudo ignoran la práctica de las redacciones y las formas complejas en que las audiencias pueden recibir los discursos y acercarse al lenguaje de estos de forma (a)crítica (véase, sin embargo, Cotter, 20Io). Consciente de este punto de vista, el presente volumen adopta una perspectiva crítica sobre los discursos en torno a temas de género, violencia y desigualdad social, pues estos pueden tener implicaciones importantes en las creencias, percepciones y el control social y público (Carter \& Steiner, 2004; Carlyle, Slater \& Chakroff, 2008).

Los doce artículos que conforman el monográfico Los discursos de género, violencia y desigualdad social en la era de la comunicación (digital) ofrecen un sólido y consistente recorrido por temas clave en la investigación sobre estudios de género, violencia y desigualdad, con enfoques metodológicos diversos. El monográfico cuenta con la autoría de 24 investigadoras e investigadores, procedentes de I4 universidades.

Movimientos de alcance global como el MeToo, surgido en 20I7, han marcado un antes y un después en el tratamiento mediático de la violencia contra las mujeres, en particular cuando los agresores pertenecen a una élite cultural hasta hace poco intocable. Ana Añó, Carme Ferré-Pavia, Maria Ballester y Julia Corbinos realizan un análisis cualitativo de 462 informaciones publicadas en los periódicos El País y El Mundo entre 2015 y 2020, en las que se alude directamente a abusos a mujeres por parte de Roman Polanski, Harvey Weinstein y Plácido Domingo. Las autoras evalúan en detalle el tono y enfoque de las informaciones a partir de un estudio del texto y los elementos de titulación, que permiten mostrar un avance en la visibilización de abusos por parte de personajes que ostentan una posición de poder. Estos resultados coinciden con otros estudios internacionales que observan un paso adelante en el silenciamiento mediático de la violencia contra las mujeres.

Como indica Giovanni Garofalo, en una época dominada por la comunicación digital, las redes se han convertido en espacios de autorrepresentación de la identidad. En la intersección entre discurso, género e identidad, los relatos eróticos homosexuales disponibles en internet constituyen un ámbito de investigación de gran interés para los estudios queer relacionados con la construcción social de la orientación sexual y de la identidad de género de personas lésbicas, gais, transgénero, bisexuales e intersexuales (LGTBI). Garofalo combina algunos conceptos centrales de la sociología y el psicoanálisis con la lingüística de corpus para analizar el papel del lenguaje en la construcción del imaginario erótico de una comunidad gay hispanohablante en internet a 
través de un corpus de relatos amateur. El estudio pretende arrojar luz sobre las representaciones simbólicas y los mecanismos discursivos que guían la co-construcción del deseo erótico homosexual, masculino y femenino. El análisis discursivo de estos relatos gais y lésbicos evidencia que la subjetividad y el deseo homosexual son un terreno de conflicto "colonizado" por el simbolismo de dominio heteronormativo.

El artículo de Adolfo Carratalá analiza el discurso de la extrema derecha contra la igualdad LGTBI, a partir de las campañas antigénero lanzadas en España por las organizaciones ultraconservadoras Foro Español de la Familia y HazteOir.org, así como el partido ultraderechista Vox. La investigación pone el foco en los mensajes canalizados a través de la red social Twitter en los dos años posteriores a la entrada de Vox en las instituciones, en un contexto de crecimiento del discurso del odio. El análisis de la transitividad del discurso de estos actores permite desvelar desde qué posición lo enuncian y qué papel juegan los participantes que aparecen en sus publicaciones. El mensaje de los tres actores analizados muestra una lógica victimista y una posición defensiva, que altera la relación de poder estructural desde la que articulan un mensaje aparentemente legítimo, que presentan como respuesta a una agresión. La inversión de la vulnerabilidad se sustenta a través de la representación de los avances hacia la igualdad de las personas LGTBI en términos de adoctrinamiento infantil, recorte de derechos y discriminación de mayorías, al tiempo que trata de enmascarar un discurso abiertamente LGTBIfóbico.

Los Juegos Paralímpicos constituyen una atalaya fundamental para evaluar la relación entre medios de comunicación y discapacidad. Sandra Meléndez-Labrador se asoma a ella desde un enfoque crítico-interpretativo para analizar los significados asignados por los deportistas paralímpicos colombianos a las noticias publicadas por los medios digitales sobre su participación en los Juegos Paralímpicos Río 20I6. Con una metodología que combina el análisis textual de noticias digitales con entrevistas semiestructuradas a 45 protagonistas de las noticias, la autora constata que la mayoría de atletas carecen de conocimiento y adopción del modelo progresista de representación mediática de la discapacidad, por lo que valoran los discursos mediáticos que los representan como héroes o modelos de inspiración, pero no por sus logros deportivos. La autora considera necesario insistir en el modelo de tratamiento mediático de la discapacidad en un "escenario de estigmatización, segregación y exclusión como lo es el paralímpico”. Aboga, además por la difusión de guías sobre la cobertura mediática del deporte para personas con discapacidad, que 
incluyan las formas, medios de expresión e interacción con los deportistas paralímpicos durante las entrevistas.

Nair Rabelo aborda el tema de la violencia sexual desde el ACD para analizar el contexto sociológico, lingüístico y legal a propósito del caso de la violación múltiple de una adolescente en Brasil cuyo vídeo fue distribuido en Twitter por uno de los agresores. La enorme repercusión social del caso impulsó la tramitación de medidas legislativas que prohíben la difusión de cualquier material audiovisual sobre este tipo de delito. Rabelo combina el ACD con las propuestas de Resende para analizar críticamente las políticas públicas en Brasil, siempre sujetas al discurso público. En concreto, el artículo propone el análisis de los tuits en los 45 días posteriores a la divulgación del vídeo centrándose en tres grupos: los medios sociales, las redes sociales y las organizaciones en defensa de los derechos de la mujer. De forma cronológica, el análisis evoluciona desde el estupor y la repulsa del crimen hasta las políticas sociales y la violencia contra las mujeres. Mediante el análisis de tuits y de debates en el parlamento brasileño, Rabelo estudia los movimientos retóricos y el uso de términos específicos que cambiaron, en parte, el tono del discurso público en torno a la violencia sexual.

La investigación reciente sobre los discursos de las redes sociales se ha centrado en su representación y percepción de las desigualdades sociales, desde los círculos exclusivamente masculinos de políticos y periodistas en Twitter hasta el elevado nivel de acoso que sufren las mujeres en las redes sociales. Carla Fernández y Aroa Orrequia abordan este último en su artículo desde una metodología mixta sobre un corpus de tuits relativos a candidatas en las elecciones generales del Reino Unido (2019), marcadas por los debates sobre el Brexit. El análisis cuantitativo de los tuits, generados a partir del debate televisado entre Boris Johnson (Partido Conservador), Jeremy Corbyn (Partido Laborista), Nicola Sturgeon (Partido Nacional Escocés), y Jo Swinson (Partido Liberal-Demócrata), revela que las colocaciones priorizan aspectos de la personalidad por encima de sus propuestas, con mayores tintes sexistas en el caso de las mujeres y con una valoración más negativa desde el análisis del sentimiento, que mide la valencia positiva o negativa de ciertos ítems léxicos. Los resultados apuntan a lo que las autoras han denominado violencia semiótica, es decir, la violencia que se codifica en los signos: el lenguaje, las imágenes, o las diferentes asociaciones de ciertos hashtags con distintos géneros. Este tipo de violencia semiótica, concluyen Fernández y Orrequia, aparta a las mujeres de la política y dificulta el acceso a otras mujeres que ven el elevado coste de participar en la vida pública. 
Como atestiguan los trabajos del presente volumen, la violencia de género posee múltiples representaciones: desde las físicas hasta las más sutiles ejercidas desde el lenguaje en diversos discursos. Entre ambas, explican Begoña Pozo-Sánchez y Carles Padilla-Carmona, todavía un amplio abanico de violencias psicológicas que incluyen las agresiones verbales, el acoso sexual, el desprecio, el chantaje emocional, la culpabilización a la anulación. Entre aquellas más sutiles, pero no menos lesivas, Pozo-Sánchez y Padilla-Carmona se refieren a la ocultación de la mujer y de cualquier éxito o avance conseguido por una mujer o un grupo de mujeres de los discursos públicos (desde los medios de comunicación hasta los textos educativos). Para combatir y nombrar (un acto político) esta ocultación de los referentes femeninos en los diferentes ámbitos del prestigio social, académico, cultural y político, estos autores han creado la palabra criptoginia.

El artículo ahonda en la interseccionalidad que afecta de forma transversal a la mayoría de los discursos producidos por mujeres donde, a pesar de que en las últimas décadas hemos asistido a cierto proceso de empoderamiento, así como a la toma de conciencia sobre la necesidad de la inclusión de la perspectiva de género en todos los espacios públicos, la sociedad ha asistido (y quizás legitimado) la perpetración de una violencia simbólica que ahora tiene nombre. Pozo-Sánchez y Padilla-Carmona trazan el recorrido del término hasta la actualidad, con su reciente inclusión en obras lexicográficas, tratamiento en congresos y reuniones científicas, artículos en prensa, etc., a la vez que exponen de forma programática una propuesta didáctica de aplicación de la perspectiva de género en la investigación, la formación y la docencia en todos los ámbitos del sistema educativo, incluidos los materiales didácticos, para garantizar la visibilidad de las aportaciones de las mujeres.

La cobertura de los asesinatos machistas, desde la perspectiva de las fuentes informativas utilizadas en su relato, centra la investigación de Ainhoa Novo-Arbona, Simón Peña-Fernández, Leyre Eguskiza-Sesumaga, Eva Jiménez-Martín y Lucía Martínez-Odriozola. A partir del análisis de las informaciones publicadas entre 2015 y 2017 por los siete diarios vascos de mayor audiencia (Berria, Deia, Diario de Noticias de Álava, Diario de Noticias de Gipuzkoa, Diario Vasco, El Correo y Gara), los datos cuantitativos se completan con diez entrevistas en profundidad semiestructuradas a personas responsables de la cobertura de los feminicidios en los medios de comunicación vascos. Los resultados de la investigación alertan sobre el uso de fuentes poco cualificadas en el tratamiento de temas sensibles como los asesinatos machistas, con el recurso mayoritario a vecindario y familias. Pese a ser conscientes 
de los peligros que entrañan estas prácticas frente al recurso a las instituciones políticas y las asociaciones feministas, los y las responsables de medios reconocen las dificultades para superar las rutinas periodísticas y ofrecer una cobertura óptima, congruentes con códigos deontológicos y libros de estilo.

Nuria Lorenzo-Dus y Keighley Perkins exploran la reproducción de estereotipos negativos con respecto a la salud mental en la prensa británica. En concreto, el artículo evalúa el cumplimiento de los códigos éticos de organizaciones como la National Union of Journalists (NUJ) en la representación de hombres que padecen esquizofrenia. Metodológicamente innovador, el análisis combina el Análisis Discursivo de Valores Noticiosos (DNVA; Bednarek \& Caple, 20I7) con el análisis de contenido y temático. Desde una aproximación retrospectiva a la representación de la salud mental en los medios, el artículo señala las conexiones implícitas y explícitas que se establecen entre salud mental y violencia, con riesgo evidente de victimización cuando los sujetos son hombres. El análisis se centra en la relación entre los valores noticiosos tales como Impacto, Magnitud, Personalización y Negatividad y las recomendaciones presentes en los códigos éticos (a saber, no discriminar, no usar un lenguaje derogatorio, no establecer vínculos entre enfermedad mental y violencia), con anterioridad y posterioridad a la aprobación del código ético en 20I4. Los resultados del estudio indican que las recomendaciones no parecen haber resultado en una mejor representación de la esquizofrenia, mostrando al contrario una tendencia a la exclusión de valores de Personalización, que suelen ser positivos y contextualizan las enfermedades mentales.

Desde sus orígenes, el ACD concibe los discursos en torno a la violencia como prácticas sociales que dan cuenta de las relaciones de dominación, discriminación, poder y control tal y como se manifiestan en el discurso. Desde el análisis lingüístico de la argumentación interaccional con una perspectiva crítica y etnográfica, Alicia E. Carrizo analiza la representación y repercusión en los medios de un caso de violencia no manifiesta en un retén policial al impedir el paso a una paciente oncológica de I2 años por la situación sociosanitaria en la provincia derivada de la pandemia de la COVID-I9. Sobre un corpus multimodal compuesto de siete notas de medios digitales, el vídeo del intercambio entre el policía y el padre y entrevistas a la familia en los medios, la autora estudia el comportamiento argumentativo y la evolución narrativa sobre la base de la teoría lingüística sistémica-funcional, desde tres dimensiones: la estructura lógica, la disputa dialéctica y la retórica persuasiva. Desde una perspectiva integral multidimensional, la autora concluye que la violencia y el abuso de poder en el posicionamiento de las personas en situación de 
sometimiento y dependencia (absoluta o relativa) cristalizadas en contextos político-sociales concretos y se manifiesta como amenaza (real o potencial) de uso de la fuerza y/o de los resortes institucionales.

Las propuestas recogidas en este volumen aportan una visión interdisciplinar desde diversos espacios de reflexión discursiva y cultural, a la vez que promueven el uso de metodologías mixtas en la investigación sobre las representaciones en los medios (digitales) en torno a cuestiones de género, violencia y desigualdad social (y sus interrelaciones), que conforman los espacios cotidianos. Con todo, el volumen invita a reflexionar sobre un conjunto de creencias, actitudes y representaciones culturalmente compartidas, que son clave para la re-significación del género, la violencia y la desigualdad social, cuyo andamiaje ideológico se crea, transmite, legitima y se resiste en y desde los medios. Esperamos que los artículos que aquí se presentan puedan a la vez conducir a futuras investigaciones en torno a la (re)configuración de estos espacios discursivos en las sociedades actuales.

\section{Bibliografía}

Bednarek, Monika \& Caple, Helen. 20I7. The Discourse of News Values: How News Organisations Create Newsworthiness. Oxford: Oxford University Press.

Bell, Alan. 1991. The Language of News Media. Oxford: Blackwell.

Bell, Alan. I998. The discourse structure of news stories. En Bell, Alan \& Garret, Peter (eds.) Approaches to Media Discourse. Oxford / Malden, MA: Blackwell, 64-IO4.

Bennet, Lance W. \& Segerberg, Alexandra. 20I2. The logic of connective action. Information, Communication and Society 15(5): 739-768.

Butler, Judith. 2006. Gender Trouble: Feminism and the Subversion of Identity. London: Routledge.

Carlyle, Kellie E.; Slater, Michael D. \& Chakroff, Jennifer L. 2008. Newspaper coverage of intimate partner violence: Skewing representations of risk. Journal of Communication 58, I68-186.

Carter, Cynthia \& Steiner, Linda. 2004. Introduction to critical readings: Media and gender. En Carter, Cynthia \& Steiner, Linda (eds.) Critical Readings: Media and Gender, I-IO.

Castells, Manuel (ed.). 20Ir. La sociedad red: una visión global. Madrid: Alianza Editorial.

Cole, Peter \& Harcup, Tony. 2010. Newspaper Journalism. London: Sage.

Cotter, Colleen. 20Io. News Talk: Investigating the Language of Journalism. Cambridge: Cambridge University Press.

Couldry, Nick. 20I2. Media, Society and World: Social Theory and Digital Media Practice. Wiley. 
Durant, Alan \& Lambrou, Marina. 2009. Language and Media: A Resource Book for Students. London / New York: Routledge.

Ehrlich, Susan; Meyerhoff, Miriam \& Janet Holmes (eds.). 20I4. The Handbook of Language, Gender and Sexuality. London: Wiley.

Fairclough, Norman. 1995. Critical Discourse Analysis. Boston: Addison Wesley.

Fairclough, Norman. 2006. Language and Globalisation. London: Routledge.

Flowerdew, John \& Richardson, John E. (eds.). 20I8. The Routledge Handbook of Critical Discourse Studies. London: Routledge.

Fowler, Roger. I991. Language in the News. Discourse and Ideology in the Press. London / New York: Routledge.

Fuchs, Christian. 2007. Towards a dynamic theory of virtual communities. International Journal of Knowledge and Learning 3(4): 372-403.

Palmer, Jerry. 2000. Spinning into Control: News Values and Source Strategies. London / New York: Leicester University Press.

Richardson, John E. 2007. Analysing Newspapers: An Approach from Critical Discourse Analysis. Basingstoke: Palgrave Macmillan.

Tabbert, Ulrike. 2016. Language and Crime: Constructing Offenders and Victims in Newspaper Reports. Basingstoke: Palgrave Macmillan.

van Dijk, Teun A. ı988. News as Discourse. Hillsdale: Lawrence Erlbaum Associates Inc.

van Dijk, Teun A. I998. Ideology. London: Sage.

van Dijk, Teun A. 2008. Discourse and Power. London: MacMillan.

Westerståhl, Jörgen \& Johansson, Folke. I994. Foreign news: News values and ideologies. European Journal of Communication 9(I): 7I-89. DOI: IO.II77/ 0267323194009001004.

Winseck, Dwayne. 20I7. The Geopolitical Economy of the Global Internet Infrastructure. Journal of Information Policy 7: 228-267.

Wodak, Ruth \& Meyer, Michael. 200I. Methods of Critical Discourse Analysis. London: Sage.

Wodak, Ruth \& Busch, Brigitta. 2004. Approaches to media texts. En Downing, John D.H. et al. (eds.) The Sage Handbook of Media Studies. London: Sage, I05-I23. 
